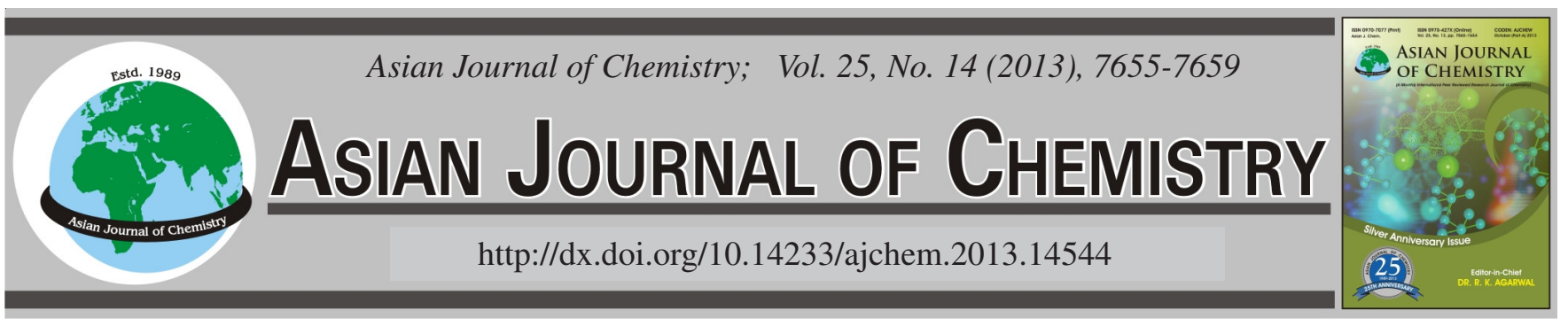

\title{
Controllable Electrochemical Synthesis of Mono- and Di-Substituted Diphosphine Complexes Related to [Fe-Fe]-Hydrogenase
}

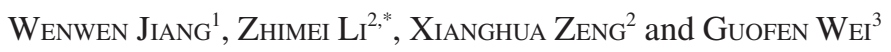

\author{
${ }^{1}$ Department of Food Science and Engineering, Nanchang University, Nanchang 330031, P.R. China \\ ${ }^{2}$ Department of Chemistry, Nanchang University, Nanchang 330031, P.R. China \\ ${ }^{3}$ Department of Mathematics, Nanchang University, Nanchang 330031, P.R. China \\ *Corresponding author: Tel: +86 13576043206; E-mail: lizhimei@ ncu.edu.cn
}

(Received: 10 September 2012;

Accepted: 8 July 2013)

AJC-13781

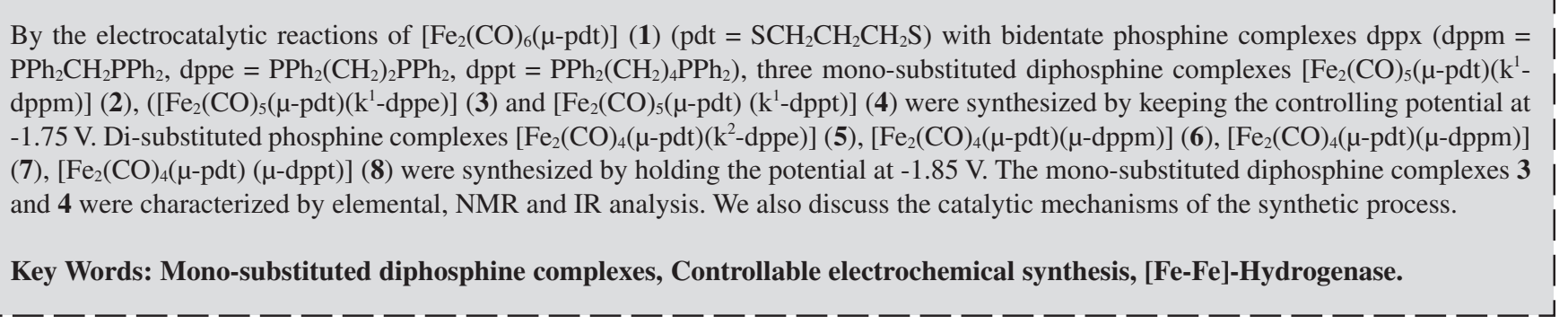

\section{INTRODUCTION}

As water is the only product in the process of oxidation of $\mathrm{H}_{2}$, dihydrogen has the potential to act as a "clean" alternative to fossil fuels. However, now-a-days, it is a fact that efficient catalysts to produce $\mathrm{H}_{2}$ usually depend on noble metals such as platinum. In nature, $[\mathrm{Fe}-\mathrm{Fe}]$-hydrogenase has an active site composed of a diiron center that is coordinated with two pairs of terminal $\mathrm{CO}$ and $\mathrm{CN}^{-}$ligands and by a carbonyl in a bridging or terminal (or semi-bridging) position ${ }^{1-3}$. [Fe-Fe]hydrogenase exhibits high efficiency and a rapid reaction rate in both the catalytic production of hydrogen or hydrogen oxidation under mild conditions ${ }^{4-7}$.

The classical complexes, dithiolate-bridged diiron complexes, $\left[\mathrm{Fe}_{2}(\mathrm{CO})_{\mathrm{n}}(\mu-\mathrm{SXS}) \mathrm{L}_{6-\mathrm{n}}\right](\mathrm{n}=6,5,4 ; \mathrm{X}=\mathrm{R}$ or $\mathrm{CH}_{2} \mathrm{~N}(\mathrm{R}) \mathrm{CH}_{2}, \mathrm{~L}=\mathrm{PPh}_{3}, \mathrm{PMe}_{3}, \mathrm{CN}^{-}$or other non-CO ligands), are structurally and functionally similiar to the active metal center of [Fe-Fe]-hydrogenase, have stimulated much active interest in their chemistry ${ }^{8}$. In the catalytic conversion of protons to hydrogen at the active centre, a key step is the protonation of the active centre. Electron-donating groups, such as $\mathrm{CN}^{-}$, can make the active center accept proton(s) easily. Since phosphine ligands have an electron-donating ability similar to that of the $\mathrm{CN}^{-}$group, a large number of phosphine-substituted derivatives have been prepared ${ }^{9,10}$. However, the production of these substituted derivatives, based on the use of decarbonylation reagents are low yielding and time consuming $^{11,12}$. It was also reported that treatment of the diiron hexacarbonyl complex $\left[\mathrm{Fe}_{2}(\mathrm{CO})_{6}(\mu-\mathrm{pdt})\right](\mathbf{1})\left(\mathrm{pdt}=\mathrm{SCH}_{2} \mathrm{CH}_{2} \mathrm{CH}_{2} \mathrm{~S}\right)$ with $\mathrm{PPh}_{2}\left(\mathrm{CH}_{2}\right)_{2} \mathrm{PPh}_{2}$ (dppe) in refluxing toluene in the presence of $\mathrm{Me}_{3} \mathrm{NO}$ afforded only the asymmetrical complex $\left[\mathrm{Fe}_{2}(\mathrm{CO})_{4}(\mu\right.$-pdt $)\left(\mathrm{k}^{2}\right.$-dppe $\left.)\right](5)$ and did not yield the monosubstituted complex $\left[\mathrm{Fe}_{2}(\mathrm{CO})_{5}(\mu\right.$-pdt $)\left(\mathrm{k}^{1}\right.$-dppe $\left.)\right](3)$. The need for more effective methods for synthesizing these complexes prompted us to do more related research ${ }^{9,12}$.

Here we report an effective method to synthesize some mono-substituted complexes, $\left[\mathrm{Fe}_{2}(\mathrm{CO})_{5}(\mu\right.$-pdt $\left.)\left(\mathrm{k}^{1}-\mathrm{dppm}\right)\right]$ (2) $\left(\mathrm{dppm}=\mathrm{PPh}_{2} \mathrm{CH}_{2} \mathrm{PPh}_{2}\right),\left[\mathrm{Fe}_{2}(\mathrm{CO})_{5}(\mu-\mathrm{pdt})\left(\mathrm{k}^{1}\right.\right.$-dppe $\left.)\right](3)$, $\left[\mathrm{Fe}_{2}(\mathrm{CO})_{5}(\mu\right.$-pdt $)\left(\mathrm{k}^{1}\right.$-dppt $\left.)\right](4)\left(\mathrm{dppt}=\mathrm{PPh}_{2}\left(\mathrm{CH}_{2}\right)_{4} \mathrm{PPh}_{2}\right)$, the asymmetrical di-substituted complexes, $\left[\mathrm{Fe}_{2}(\mathrm{CO})_{4}(\mu\right.$-pdt $)\left(\mathrm{k}^{2}-\right.$ dppe)] (5) and the symmetrical di-substituted complexes $\left[\mathrm{Fe}_{2}(\mathrm{CO})_{4}(\mu\right.$-pdt $)(\mu$-dppm) $](\mathbf{6}),\left[\mathrm{Fe}_{2}(\mathrm{CO})_{4}(\mu\right.$-pdt $)(\mu$-dppm $\left.)\right](7)$ and $\left[\mathrm{Fe}_{2}(\mathrm{CO})_{4}(\mu\right.$-pdt $)(\mu$-dppt $\left.)\right](\mathbf{8})$ by selecting the appropriate potential. The key feature of these processes is their selectivity We also discuss in this paper the possible mechanisms of the processes from the mono-substituted complexes to the disubstituted complexes.

\section{EXPERIMENTAL}

General procedures: All the experiments were carried out under argon atmosphere. Solvents were dried and distilled according to the standard methods. $\left[\mathrm{Fe}_{2}(\mathrm{CO})_{6}(\mu-\mathrm{pdt})\right],(\mathbf{1})$, 
was prepared as described in the literature ${ }^{13}$. The purification of product was carried out with Schlenk technique.

Infrared spectra were recorded on a scimitar series Varian 2000 FT-IR. Elemental analyses were performed using an Elementar vario MICRO instrument. ${ }^{1} \mathrm{H}$ and ${ }^{31} \mathrm{P}$ NMR spectra were recorded on a Varian INOVA $400 \mathrm{mHz}$ NMR instrument.

Electrochemistry: Electrochemistry was carried out under an argon atmosphere in freshly dried dichloromethane using an Autolab Potentiostat 30. A conventional threeelectrode system was employed in which a Pt disk $(\phi=1 \mathrm{~mm})$ was used as the working electrode, a vitreous carbon strip as the counter electrode and an $\mathrm{Ag} / \mathrm{AgCl}$ (Metrohm) as the reference electrode. The inner reference solution is composed of $0.05 \mathrm{M}\left[\mathrm{NBu}_{4}\right] \mathrm{Cl}$ and $0.45 \mathrm{M}\left[\mathrm{NBu}_{4}\right] \mathrm{BF}_{4}$. The preparation and purification of the supporting electrolyte $\left[\mathrm{NBu}_{4}\right] \mathrm{BF}_{4}$ was described previously ${ }^{14}$. All the potentials were measured against the ferrocene-ferrocenium couple, which was added as an internal standard at the end of the experiments.

In dichloromethane, the electrolyte is $0.5 \mathrm{M}\left[\mathrm{NBu}_{4}\right] \mathrm{BF}_{4}$ to ensure optimum conductivity of the solution. When carrying out bulk electrolyses, with a vitreous carbon strip $\left(2 \mathrm{~cm}^{2}\right)$ as the working electrode, all coulometric experiments were performed at constant potential under an argon atmosphere and were followed by periodically measuring the cyclic voltammogram in situ or extracting an aliquot of the catholyte for IR analysis.

Electrosynthesis: Electrosynthesis of $\left[\mathrm{Fe}_{2}(\mathrm{CO})_{5}(\mu-\mathrm{pdt})\right.$ $\left.\left(\mathrm{k}^{1}-\mathrm{dppm}\right)\right],\left[\mathrm{Fe}_{2}(\mathrm{CO})_{5}(\mu-\mathrm{pdt})\left(\mathrm{k}^{1}-\mathrm{dppe}\right)\right]$ and $\left[\mathrm{Fe}_{2}(\mathrm{CO})_{5}(\mu-\mathrm{pdt})\right.$ $\left.\left(\mathrm{k}^{1}-\mathrm{dppt}\right)\right]$.

Three three-chambered electrolysis cells filled with argon were charged with $0.100 \mathrm{~g}(0.26 \mathrm{mmol})\left[\mathrm{Fe}_{2}(\mu\right.$-pdt $\left.)(\mathrm{CO})_{6}\right], 1$ and $0.100 \mathrm{~g}(0.26 \mathrm{mmol}) \mathrm{dppm} / 0.103 \mathrm{~g}(0.26 \mathrm{mmol}) \mathrm{dppe} /$ $0.112 \mathrm{~g}(0.26 \mathrm{mmol}) \mathrm{dppt}$ in $10 \mathrm{~mL}$ of dichloromethane containing $0.5 \mathrm{M} \mathrm{TBA} \mathrm{BF}_{4}$. The cathodic current at constant potential of $-1.75 \mathrm{~V}$ was passed through the solution until the cathodic current of the cells in the potentiostatic experiment decayed to the background level, or the cathodic current was observed to be relatively invariant at $-0.03 \mathrm{~mA}$ for $c a .15 \mathrm{~min}$ (passage of $0.24 \mathrm{C} / 2.66 \mathrm{C} / 3.49 \mathrm{C}$ ). The cathodic electrolyte was monitored by IR. The solvent was removed in vacuo. The red solid residue was washed with hexane $(3 \mathrm{~mL} \times 3 \mathrm{~mL})$ to remove any remaining starting material. The solid was then purified by column chromatography on a silica gel column by elution with 10:1 v/v mixture of ethyl acetate and petroleum ether. Removal of solvent in vacuo, yielded a red solid, $90 \%$ $(0.173 \mathrm{~g}) / 92 \%(0.181 \mathrm{~g}) / 87 \%$ (0.180 g), respectively. Crystallization twice from dichloromethane afforded a red solid for IR analysis.

Product 2: IR (vCO) $\left(\mathrm{CH}_{2} \mathrm{Cl}_{2}\right): 2043$ m, 1982 vs, 1956 sh, $1924 \mathrm{w} \mathrm{cm}^{-1}$.

Product 3: IR (vCO) $\left(\mathrm{CH}_{2} \mathrm{Cl}_{2}\right): 2044 \mathrm{~m}, 1982$ vs, 1962 sh, $1927 \mathrm{w} \mathrm{cm}^{-1} .{ }^{1} \mathrm{H} \mathrm{NMR}\left(\mathrm{CDCl}_{3}\right)$ : $\delta 7.79-7.36\left(\mathrm{~m}, 20 \mathrm{H}, \mathrm{C}_{6} \mathrm{H}_{5}\right)$, 3.19 (m, 4H, $\left.\mathrm{PCH}_{2} \mathrm{CH}_{2} \mathrm{P}\right), 2.56(\mathrm{~m}, 4 \mathrm{H}, \mu-\mathrm{pdt}), 1.64$ (m, 2H, $\mu-$ pdt) ppm. ${ }^{31} \mathrm{P} \mathrm{NMR}\left(\mathrm{CDCl}_{3}\right): \delta$ (s) 59.6, $32.4 \mathrm{ppm}$. Anal. calcd. (\%) for $\mathrm{C}_{34} \mathrm{H}_{30} \mathrm{O}_{5} \mathrm{P}_{2} \mathrm{~S}_{2} \mathrm{Fe}_{2}$ : C, 53.97; H, 3.97. Found (\%): C, 54.36; H, 4.01.

Product 4: IR (vCO) $\left(\mathrm{CH}_{2} \mathrm{Cl}_{2}\right): 2043 \mathrm{~s}, 1982 \mathrm{vs}, 1956 \mathrm{sh}$, $1925 \mathrm{~m} \mathrm{~cm}^{-1} .{ }^{1} \mathrm{H} \mathrm{NMR}\left(\mathrm{CDCl}_{3}\right): \delta 7.62\left(\mathrm{~m}, 8 \mathrm{H}, \mathrm{C}_{6} \mathrm{H}_{5}\right), 7.41(\mathrm{~m}$, $\left.12 \mathrm{H}, \mathrm{C}_{6} \mathrm{H}_{5}\right), 2.45$ (m, 4H, $\left.\mathrm{PCH}_{2}\right), 1.85(\mathrm{~m}, 4 \mathrm{H}, \mu-\mathrm{pdt}), 1.52$ (m,
$2 \mathrm{H}, \mu$-pdt $), 1.85\left(\mathrm{~m}, 4 \mathrm{H}, \mathrm{CH}_{2}\right), \mathrm{ppm} .{ }^{31} \mathrm{P} \mathrm{NMR}\left(\mathrm{CDCl}_{3}\right): \delta(\mathrm{s})$ 57.6, $-26.0 \mathrm{ppm}$.

Electrosynthesis of $\left[\mathrm{Fe}_{2}(\mathrm{CO})_{4}(\mu-\mathrm{pdt})\left(\mathrm{k}^{2}\right.\right.$-dppe $\left.)\right]$, $\left[\mathrm{Fe}_{2}(\mathrm{CO})_{4}(\mu\right.$-pdt $)(\mu$-dppm) $],\left[\mathrm{Fe}_{2}(\mathrm{CO})_{4}(\mu\right.$-pdt $)(\mu$-dppe $\left.)\right]$ and $\left[\mathrm{Fe}_{2}(\mathrm{CO})_{4}(\mu-\mathrm{pdt})(\mu-\mathrm{dppt})\right]$.

A similar procedure to that described above was carried out to synthesize the complex di-substituted diphosphine complexes at a constant potential of $-1.85 \mathrm{~V}$. Upon disappearance of the IR band at $2044 \mathrm{~cm}^{-1}$ the reaction was continued for an addtitional $5 \mathrm{~min}$ and then a sample of the solution again checked by IR. After purification, three products were obtained with yields of $65 \%$ (121 mg) for product 6, $75 \%$ $(142 \mathrm{mg})$ for product 7 and $71 \%(139 \mathrm{mg})$ for product 8. Product 6: IR (vCO) $\left(\mathrm{CH}_{2} \mathrm{Cl}_{2}\right): 1987 \mathrm{~m}, 1956 \mathrm{vs}, 1919 \mathrm{~s}, 1901$ sh. Product 7: IR (vCO) $\left(\mathrm{CH}_{2} \mathrm{Cl}_{2}\right): 1990 \mathrm{~s}, 1954 \mathrm{vs}, 1920 \mathrm{~s}$, 1901 w. Product 8: IR (vCO) $\left(\mathrm{CH}_{2} \mathrm{Cl}_{2}\right): 1990$ s, 1943 vs, 1925 $\mathrm{s}$ and $1886 \mathrm{~m}$.

The electrolysis reaction was monitored by IR and then stopped upon disappearance of the IR band at $2044 \mathrm{~cm}^{-1}$. After the mixture was purified by column chromatography, two products 5 and $\mathbf{7}$ were obtained. The yields of products $\mathbf{5}$ and 7 were $27 \%(51 \mathrm{mg})$ and $61 \%(117 \mathrm{mg})$, respectively.

Product 5: IR $\left(\mathrm{cm}^{-1}\right)(\mathrm{vCO})\left(\mathrm{CH}_{2} \mathrm{Cl}_{2}\right): 2019 \mathrm{~s}, 1949 \mathrm{~s}$ and 1905 w.

\section{RESULTS AND DISCUSSION}

Electrosynthesis of mono- and di-substituted diphosphine complexes: The diiron hexacarbonyl complex 1 was not reactive towards diphosphines at room temperature before electrolysis. However, the reactions of complex 1 with diphosphines occurred rapidly if the electrodes [ $\mathrm{Ag} / \mathrm{AgCl}]$ were simply inserted into the solutions and negative potentials were applied. The value of the potential determined the selectivity of the products. Table- 1 showed that mono-substituted diphosphine complexes 2, 3 and $\mathbf{4}$ were obtained at $-1.75 \mathrm{~V}$ (Scheme-I) and di-substituted diphosphine complexes 5, 6, 7 and $\mathbf{8}$ were obtained at $-1.85 \mathrm{~V}$ in the solution of complex $\mathbf{1}$ with diphosphines (Scheme-II). Isolation of these products was followed by IR analysis. Fig. 1 shows the IR spectra of the solutions of complex 1 with dppe at $-1.75 \mathrm{~V}$ and $-1.85 \mathrm{~V}$ before and after electrolysis, respectively. The carbonyl region IR spectra of complexes synthesized at $-1.75 \mathrm{~V}$ were identical to the mono-substituted diphosphine complexes and were also similar to results reported in the literature ${ }^{15}$. The carbonyl region IR spectra of the complexes induced at -1.85 $\mathrm{V}$ are consistent with the di-substituted diphosphine complexes reported in the literature ${ }^{9,12,16}$. The yields of these reactions are listed in Table-1.

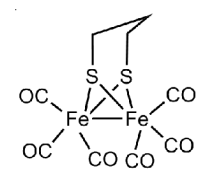

1

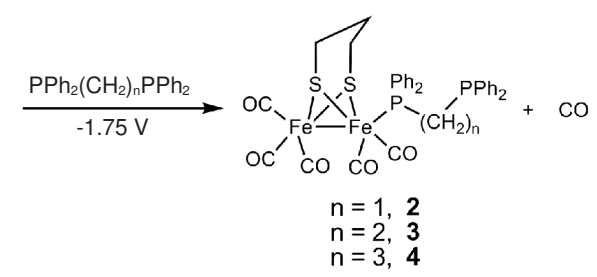

Scheme-I: Process of mono-substituted diphosphine complexes 2, 3 and 4 were synthesised by the electrocatalytic reactions 


\begin{tabular}{cccccc}
\hline \multicolumn{5}{c}{ TABLE-1 } \\
\multicolumn{5}{c}{ ETC CATALYSIS OF DIPHOSPHINE } \\
SUBSTITUTION OF COMPLEX 1 OF 0.26 mmol & \\
\hline Ligand & Potential (V) & Product & Yield (\%) & Charge & TN \\
\hline \multirow{2}{*}{ dppe } & -1.75 & $\mathbf{3}$ & 92 & & \\
& -1.85 & $\mathbf{5}$ and $\mathbf{7}$ & 27 and 61 & $0.24 \mathrm{C}$ & \multirow{2}{*}{435} \\
& - & $\mathbf{7}$ & 75 & & \\
\hline \multirow{2}{*}{ dppm } & -1.75 & $\mathbf{2}$ & 90 & \multirow{2}{*}{$2.66 \mathrm{C}$} & \multirow{2}{*}{94.3} \\
\hline \multirow{2}{*}{ dppt } & -1.85 & $\mathbf{6}$ & 65 & & \\
& -1.75 & $\mathbf{4}$ & 87 & \multirow{2}{*}{ 3.49C } & \multirow{2}{*}{71.9} \\
\hline
\end{tabular}

periodically sampling the catholyte and measuring the disappearance of the carbonyl band at $2074 \mathrm{~cm}^{-1}$ of complex 1 in the infrared spectrum. More conveniently, the cathodic currents in the potentiostatic experiment were observed to be relatively invariant at $-0.03 \mathrm{~mA}$ for approximately $5 \mathrm{~min}$. The latter observation signaled the completion of these substituted reactions, as confirmed by IR analysis of the catholyte. Turnover numbers (TN) in excess of 43.5, 94.3 and 71.9 equiv of the three mono-substituted complexes 2-4 per electron were obtained (eqn. 1).

It should be noted that asymmetric di-substituted comp-

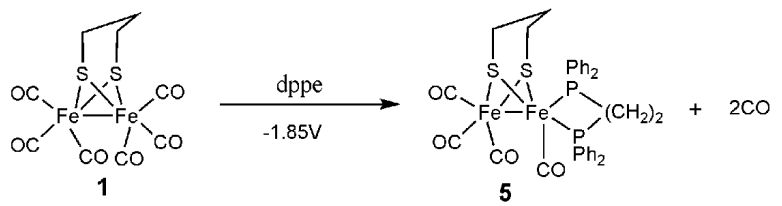

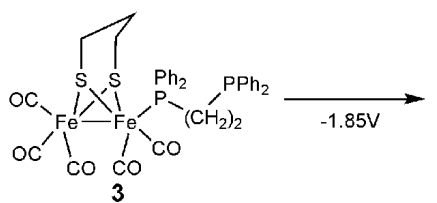

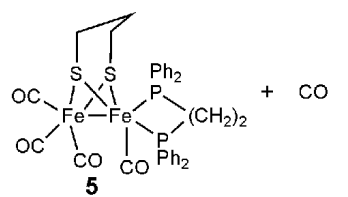
lexes were only observed in the dppe solution, an observation confirmed by periodically sampling some catholyte for IR analysis during the electrocatalytic reactions. At the beginning of the electrocatalytic synthesis of complex 1 with dppe or complex 3, the IR spectrum of the carbonyl region of the product was similar to the asymmetric di-substituted ${ }^{9}$ complex, $\mathbf{5}$, which suggested that the reaction was followed by eqns. 2 or 3. During the electrocatalytic synthesis at $-1.85 \mathrm{~V}$ in dppe solution, the sharp peak at $2019 \mathrm{~cm}^{-1}$ disappeared completely and a series of new peaks emerged, indicative of a symmetrical di-substituted complex; the final product $7^{16}$ exhibits symmetrical di-substitution (eqn. 4). The complex 5 is an intermediate between the mono-substituted diphosphine complex $\mathbf{3}$ and the symmetrical diphosphine complex 7. Unlike the dppm and dppt ligands, the mono-substituted diphosphine complexes 2 and 4 were transformed directly to the symmetrical diphosphine complexes $\mathbf{6}$ and $\mathbf{8}$, as shown in eqn. 5 .

As mono-substituted complexes $\mathbf{3}$ and $\mathbf{4}$ were novel, they were characterized by elemental, ${ }^{1} \mathrm{H}$ and ${ }^{31} \mathrm{P}$ NMR analysis.
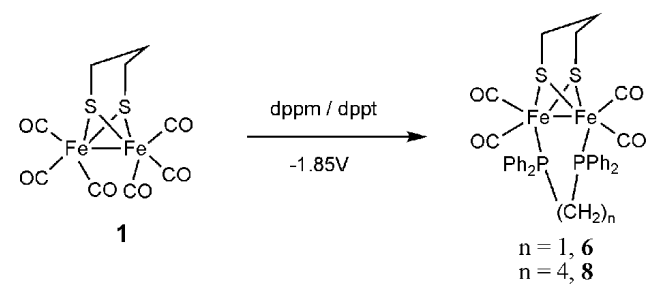

Scheme-II: Electrocatlytic synthesis of di-substituted diphosphine complexes 5, 6, 7 and 8

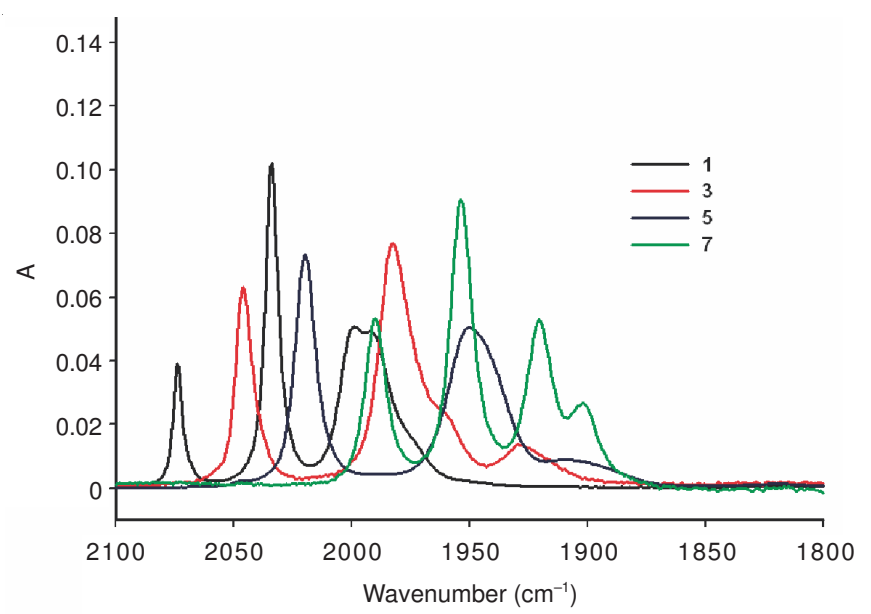

Fig. 1. IR spectrum of the complex 1 and the electrostimulated products $(3,5,7)$ of complex 1 with dppe at -1.75 and $-1.85 \mathrm{~V}$, respectively

To monitor for completion of the electrocatalytic reaction during bulk electrolysis at constant potential, the reaction course of the electrocatalytic displacement was followed by
Electrochemistry of electrosynthesis of mono- and disubstituted diphosphine complexes and their possible mechanisms

Electrochemistry of electrosynthesis of mono-substituted diphosphine complexes: Previous studies of the substitution of complex 1 with monophosphines showed that anionic species were involved in the ETC process ${ }^{17}$. In order to assess whether the substitution of $\mathbf{1}$ with diphosphines is also a possibility for the ETC process, it is necessary to discuss the electrochemical reduction. As such, we examined the cathodic behaviour of the parent complex 1 both in the absence and in the presence of the diphosphines. Fig. 2 shows cyclic voltammograms of complex $\mathbf{1}$ in the absence (dashed line) and in the presence (solid line) of dppe and the mono-substituted complex $\mathbf{3}$ (dashed-dotted line). Compared to complex 1 (dashed line), strengthen of the current of the solution of complex 1 with dppe at $-1.78 \mathrm{~V}$ (dashed line) weakened evidently. Two novel peaks occurred under the more negative potentials of -1.97 and $-2.36 \mathrm{~V}$. Apparently, the peak at -1.78 $\mathrm{V}$ is associated with the complex 1. Its detailed mechanism has been investigated by Stephen and his co-workers ${ }^{18}$. They confirmed that the reduction process of complex 1 was a twoelectron process and the anionic $\mathbf{1}$ was a short-lived species. As shown in Fig. 2 (dash-dotted line), complex 3 was reduced at -1.97 and $-2.36 \mathrm{~V}$. Evidently, the new peaks in Fig. 2 are associated with the mono-substituted complex 3 . For complex 1 with dppm or dppt, it had similar electrochemical behaviour with dppe. The electrocatalytic mechanisms of CO 


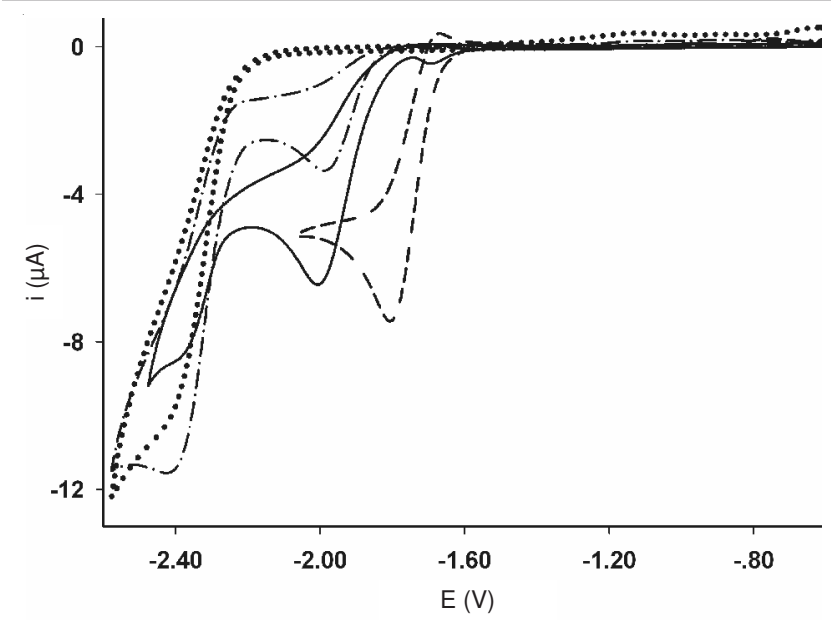

Fig. 2. Cyclic voltammograms of complex $1(0.03 \mathrm{mmol})$ in the absence (dashed line) and in the presence of dppe $(0.04 \mathrm{mmol})$ (solid line), mono-substituted complex $\mathbf{3}$ (dashed-dotted line) and the solution of the complex 1 with dppe after electrolysis at $-1.85 \mathrm{~V}$ (dotted line)

replaced by diphosphines at $-1.78 \mathrm{~V}$ seem to correspond with our previous studies (Fig. 3) ${ }^{19}$.

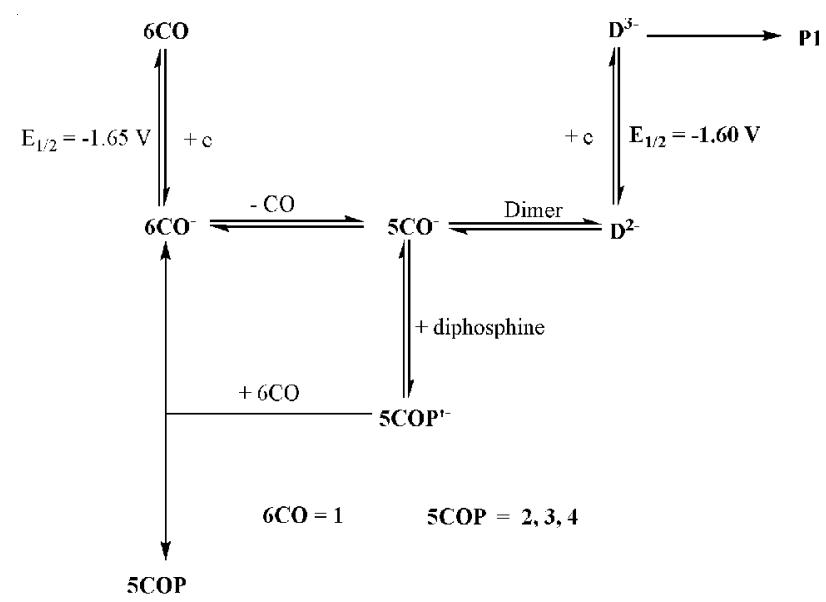

Fig. 3. Mechanism of the electrochemistry of complex $\mathbf{1}$ with diphosphines

Electrochemistry of mono-substituted complexes 2, 3, 4 and their possible mechanisms: In Fig. 2, two cathodic peaks are seen at -1.97 and $-2.36 \mathrm{~V}$ in the solution of the monosubstituted complex 3 . The peak at $-1.97 \mathrm{~V}$ is associated with the reduced complex 3 . Generally, the reduction of the monosubstituted pentacarbonyl diiron complex is assigned to a two-electron process ${ }^{20}$. As mentioned above, when the potential of $-1.85 \mathrm{~V}$ was applied to the solution of complex 1 with diphosphines or complex $\mathbf{3}$, di-substituted complexes were obtained. This indicated that the reduction of the monosubstituted complex $\mathbf{3}$ was followed by the loss of CO. In the three mono-substituted complexes, asymmetric di-substituted complexes were obtained only from the anionic product of complex 3 and under bulk electrolysis, the asymmetric disubstituted complex $\mathbf{5}$ transformed into another isomer, symmetric di-substituted complex 7 . The nature of the reaction of mono-substituted complex leading to a range of products is dependent upon the backbone flexibility of the diphosphine. For diphosphines with a single methylene backbone (dppm), symmetrically di-substituted complexes are thermodyna- mically favoured. Likewise, diphosphines with rigid twocarbon backbones such as dppe should favour asymmetrical chelating coordination thus affording electronic and steric asymmetry to the diiron centre ${ }^{15}$. Talarmin and his coworkers have reported on the mechanism of the asymmetrical complex 5 to symmetrical complex $7^{16}$. Herein, we focus on the mechanism of the transformation of the mono-substituted complex $\mathbf{3}$ into the asymmetric di-substituted complex $\mathbf{5}$ as shown in Fig. 4.

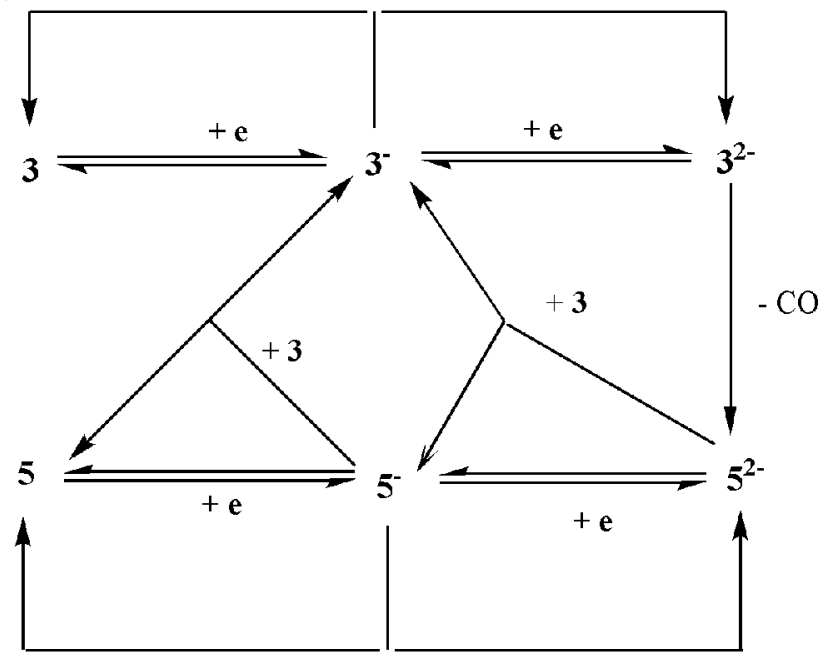

Fig. 4. Possible mechanism of the electrochemical transformation of the mono-substituted complex $\mathbf{3}$ to the asymmetric di-substituted complex 5

\section{Conclusion}

In this paper, we reported the successive synthesis of mono- and di-substituted diphosphine complexes by controlling the potential. We obtained three mono-substituted diphosphine complexes 2, 3 and 4; an asymmetric di-substituted diphosphine complex $\mathbf{5}$ and three symmetric di-substituted diphosphine complexes $\mathbf{6 , 7 , 8}$, in good yield and with shorter reaction times. We also discussed the mechanisms of these catalytic processes.

\section{ACKNOWLEDGEMENTS}

The authors thank the Natural Science Foundation of China (Grant No. 20871064) and Centre of Analysis and Testing at Nanchang University (2009001) for supporting this work. Thanks are also due to Mr. Edmund Sorenson for editing the paper.

\section{REFERENCES}

1. A.S. Pandey, T.V. Harris, L.J. Giles, J.W. Peters and R.K. Szilagyi, J. Am. Chem. Soc., 130, 4533 (2008).

2. A. Volbeda, M.H. Charon, C. Piras, E.C. Hatchikian, M. Frey and J.C. Fontecillacamps, Nature, 373, 580 (1995).

3. S. Shima, O. Pilak, S. Vogt, M. Schick, M.S. Stagni, W. Meyer-Klaucke, E. Warkentin, R.K. Thauer and U. Ermler, Science, 321, 572 (2008).

4. J.W. Peters, W.N. Lanzilotta, B.J. Lemon and L.C. Seefeldt, Science, 282, 1853 (1998).

5. Y. Nicolet, A.L. de Lacey, X. Vernede, V.M. Fernandez, E.C. Hatchikian and J.C. Fontecilla-Camps, J. Am. Chem. Soc., 123, 1596 (2001).

6. D.J. Evans and C.J. Pickett, Chem. Soc. Rev., 32, 268 (2003).

7. E. Garcin, X. Vernede, E.C. Hatchikian, A. Volbeda, M. Frey and J.C. Fontecilla-Camps, Structure, 7, 557 (1999). 
8. X.M. Liu, S.K. Ibrahim, C. Tard and C.J. Pickett, Coord. Chem. Rev., 249, 1641 (2005).

9. S. Ezzaher, J.F. Capon, F. Gloaguen, F.Y. Petillon, P. Schollhammer and J. Talarmin, Inorg. Chem., 46, 3426 (2007).

10. A.K. Justice, G. Zampella, L. De Gioia, T.B. Rauchfuss, J.I. van der Vlugt and S.R. Wilson, Inorg. Chem., 46, 1655 (2007).

11. J.F. Capon, F. Gloaguen, P. Schollhammer and J. Talarmin, $J$. Electroanal. Chem., 595, 47 ( 2006).

12. F.I. Adam, G. Hogarth, S.E. Kabir and D. Richards, Comp. Ren. Chim., 11, 890 (2008)

13. A. Winter, L. Zsolnai and G. Huttner, Z. Naturforsch. B: J. Chem. Sci., 37, 1430 (1982)
14. Z.M. Li, X.H. Zeng, Z.G. Niu and X.M. Liu, Electrochim. Acta, 54, 3638 (2009).

15. F.I. Adam, G. Hogarth and I. Richards, J. Organomet.Chem., 692, 3957 (2007).

16. S. Ezzaher, J.F. Capon, F. Gloaguen, F.Y. Petillon, P. Schollhammer and J. Talarmin, Inorg. Chem., 46, 9863 (2007).

17. D.H. Evans, Chem. Rev., 108, 2113 (2008).

18. S.J. Borg, T. Behrsing, S.P. Best, M. Razavet, X.M. Liu and C.J. Pickett, J. Am. Chem. Soc. 126, 16988 (2004).

19. X.H. Zeng, Z.M. Li and X.M. Liu, Electrochim. Acta, (Communicated).

20. D. Morvan, J.F. Capon, F. Gloaguen, P. Schollhammer and J. Talarmin, Eur. J. Inorg. Chem., 5062 (2007). 